\title{
Strengthening Transparency in Regulatory Science: The Environmental Protection Agency's Proposal to Internally Regulating Science
}

\author{
R. Samuel Herron ${ }^{*}$, Jonathan Klonowski ${ }^{2 *}$, Cassandra Rios ${ }^{2 *}$ \\ ${ }^{1}$ University of Pittsburgh School of Medicine, Department of Pathology, Pittsburgh, PA \\ 2University of Pittsburgh School of Medicine, Department of Developmental Biology, Pittsburgh, PA \\ *All authors contributed equally \\ http://doi.org/10.38126/JSPG170113 \\ Corresponding author: jok119@pitt.edu \\ Keywords: EPA; regulations; regulatory policy; peer-review; validation; transparency; executive branch
}

\begin{abstract}
Executive Summary: Policy decisions by the Environmental Protection Agency (EPA) should be informed by consulting the most relevant and updated information. Accordingly, the quality of information used is an integral part of federal decision-making as it can add credibility to policy. In 2018, EPA proposed the "Strengthening Transparency in Regulatory Science" rule (EPA-STRS, updated March 2020) as an effort to assess the quality of studies used by EPA and increase transparency in policy-making decisions through conducting publicly accessible peerreviews of all data and models. Herein we detail three arguments detailing differing perspectives on EPA-STRS and determine that, while the proposed rule purportedly seeks to strengthen the scientific underpinning of EPA policy, the current language risks the integrity of the agency's policy-making process. EPA-STRS neither adequately details methodology with which independent validation would occur, nor delineates how valid exceptions to this rule would be identified in an unbiased manner. Furthermore, the implementation of this rule as currently written would allow for the politicization of EPA policymaking through abuse of the scientific study screening process. We propose that EPA amend EPA-STRS to reduce ambiguity, minimize biases, and address concerns related to independent research validation and peer review.
\end{abstract}

\section{Background}

The scientific community is experiencing a global increase in overall publication output alongside biased data caused by selective interpretations or incorrect analysis (White et. al. 2017; Horgan 2015). Furthermore, there is concern over the open availability of data and a growing body of irreproducible studies threatening public confidence in science (NAS 2018). In direct response to the challenges posed by this replication crisis, the Office of Management and Budget, Executive Office of the President (OMB) released the 2004 Final Information Quality Bulletin for Peer Review detailing the need for stringent peer review processes under the Federal Government (Bolten 2004). This bulletin is cited as the basis for the 2018 rule, proposed by the Environmental Protection Agency (EPA) under Administrator Scott Pruitt, named "Strengthening Transparency in Regulatory Science" (EPA-STRS, 83 FR 18768). EPA claimed that the authority for the rule change is granted under 5 USC $\S 301$, which states "an Executive department ... may prescribe regulations for the government of his department".

In April 2018, EPA-STRS was submitted to the Federal Register and solicited public comment as mandated by the Administrative Procedures Act ( 5 USC $\S 551$ ). In the initial proposal of the rule, EPA sought to resolve the scientific transparency issue by requiring all raw data be available, without exclusion, 
as a prerequisite for use in the regulation. Further plans were made for these data to be publicly available on an online database. Additionally, EPA noted their intention to revalidate dose-dependent based models of scientific information to corroborate regulatory actions. In response, EPA received over 590,000 comments, many of which criticized the lack of clarity throughout the document, as well as directives contradicting current data protection laws (Reilly 2019; Brugger 2020).

In March 2020, the current EPA Administrator Andrew Wheeler submitted a Supplemental Notice of Proposed Rulemaking (SNPRM) for EPA-STRS, addressing a number of complaints regarding the poorly defined scope, as well as expanding the science covered by the rule to include all data and models used for the creation of regulation(s)(85 FR $15396 \S 30.5)$. The comment period deadline was extended from April 2020 to May 2020 due to the Covid-19 pandemic. Comments pertaining to EPA's authority for this rule - whether to singularly call 5 USC $\S 301$ as the authority or in conjunction with additional environmental statutory provisions - were of particular interest to the agency. The SNPRM received 397,000 comments, adding to the nearly 590,000 comments received on the initial 2018 proposal. Once again, an overwhelming proportion of the comments expressed opposition to the rule.

Currently, EPA-STRS stands in the proposal stage from which a finalized rule could be implemented, scrapped, or another SNPRM posted. If the rule is implemented, it is expected to receive legal challenge under the pretext that: (1) all unique comments have not been addressed, (2) the proposal still lacks a viable rationale, (3) the alternative weighting system is arbitrary and unnecessary, (4) the changes do not fall under the authority provided by 5 USC $\S 301$, and (5) the rule did not address a need (Departmental Regulations 1958; Bloomer 2020; Bergeson and Campbell, PC 2020).

\section{Potential pathways for EPA-STRS}

\section{i. Accept the proposal as is}

Proponents of EPA-STRS note that EPA is within its rights to execute housekeeping authority. This proposed rule addresses the "replication crisis" faced by the scientific community as independent validation "will lead to better outcomes, and strengthen public confidence in the health and environmental protections underpinning EPA's regulatory actions" (85 FR 15396). Considering the breadth of data and models used in the development of significant EPA regulations, it is crucial to independently validate key findings and ensure the quality of published information before use. Furthermore, EPA's proposed steps toward transparency are an agenda shared with experts who state that methods used to obtain and analyze data, as well as availability of the data used, are critical factors to reproducibility in science (Miłkowski, Hensel, and Hohol 2018).

After the initial comment period, critics opposed to EPA-STRS expressed concerns regarding the infringement of data protected by the Freedom of Information Act Exemption 4 (FOIA, 5 USC $\S 552$ ), designed to protect privileged information, and Title II of the Health Insurance Portability \& Accountability Act of 1996 (HIPPA 69 FR 78719), that outlines a person's right to confidentiality. However, EPA addressed these matters by proposing a tiered access system, thereby protecting personal data and other sensitive information. Such a system has already been implemented at the Research Data Center (RDC), thus serving as a possible scaffold for EPA's venture into storage of publicly available data (NIH 2018).

\section{ii. Reject the proposal}

As presently proposed, the decision-making surrounding implementation of peer-review and potential exceptions to EPA-STRS rests solely in the hands of the Director of EPA (Allison and Fineberg 2020). Critics have noted that this structure not only precludes checks and balances but also that the directorship is a politically appointed position which does not require the appointee to have any scientific background (Oreskes 2019; Mcintyre 2020). As such, this allows for EPA to circumvent scientific assessment regarding data usage due to this lack of structure and selective implementation of data standards and expertise. Furthermore, as currently defined this system leaves the fate of many viable studies, which no longer have accessible data sets due to their age being ambiguous (Allison and Fineberg 2020).

While ostensibly designed to address issues stemming from biases in scientific work, the proposal is structured only in regard to computational 
reproducibility, and fails to recognize or address other aspects of scientific work that contribute to biases, such as issues stemming from the study design, assumptions taken, or the merit of the conclusions drawn from the work (Allison and Fineberg 2020; Ioannidis 2018). All scientific studies suffer from limitations inherent in their design and scope (Lilford et al. 2001). An appropriate EPA-STRS proposal would address multiple aspects of scientific bias, something the currently proposed EPA-STRS fails to do.

In addition to only addressing a limited scope of scientific bias, the current structure of EPA-STRS presents a potential new source of bias and politicization that undercuts the stated goals of the proposal. Commenters expressed concern with the meaning and methods of independent verification of previous work. Furthermore, EPA-STRS does not offer a publicly transparent methodology for independent verification to avoid bias (Allison and Fineberg 2020). While EPA has taken steps to clarify the meaning of the terminology "independent validation," the proposal does not provide criteria for selection or vetting the entities responsible for independent validation (85 FR 15396).

Likewise, the concept that EPA-STRS increases oversight by enhancing the peer review process is an erroneous claim, as EPA-STRS does not substantively add to preexisting peer review criteria. EPA-STRS articulates peer review guidelines consistent with the 2004 "Final Information Quality Bulletin for Peer Review" (Bolten 2004). The proposal does not set forth any specifics for enhancing this peer review process - leaving broad discretion to the agency with regards to the extent of peer review needed - as well as the identity of the reviewer (85 FR 15396). Such guidelines fail to adequately address potential misuses of the peer review process that could arise from insufficient peer review validation (as defined by consensus in each scientific field) (Nature Neuroscience 1999). Nor does it address concerns over potential for abuse of the peer review process arising from insufficient oversight during reviewer selection. Therefore, EPA-STRS fails to properly implement a regimented peer review pipeline fortified against manipulation or misuse. These issues are unlikely to be resolved as EPA does not have the expertise to unilaterally solve these issues of peer-review. iii. Alter the proposal

The original EPA-STRS rule proposal (83 FR 18768) stunned people of the scientific community and beyond (see submitted comments to EPA-STRS; Allison and Fineberg 2020; Brugger 2020; Friedman 2019; Reilly 2020). A synthesis of the feedback suggests that, at best, the proposal was ill-conceived, and, at worst, it was a blatant attack on the scientific underpinning of the agency's environmental protections. Scientists are well aware of reproducibility and accessibility issues within the scientific profession, as well as the potential impacts of these issues on society. In response, the community has been adamantly working to overcome such challenges (Baker 2015; Berry 2016; Nature 2016; Nature 2014). Despite this, it is reasonable to implement additional governmental safeguards to both ensure accuracy and maintain public trust when developing regulations.

While the March 18, 2020 supplemental revision (85 FR 15396) marked improvements over the original, if implemented as is, the rule would only exacerbate issues it is claiming to tackle. Currently, EPA-STRS suffers from two fatal flaws, both of which can be fixed with diligent revisions. First (1), as written the rule can be exploited to undermine regulations by arbitrarily restricting scientific studies such as landmark historical studies. In the 2020 supplemental changes, EPA attempted to address criticism (1) by revising $\S 30.9$ to include an opportunity for the exception of data and models released before the effective date of the current rule (85 FR 15396). Despite this amendment, the language states that exceptions are only granted on a case by case basis by the Administrator, leaving all decisions to a politically appointed official. Changing this process to allow for appropriate scientific experts to make the assessment can easily solve this issue.

Second (2), the vagueness surrounding the terms "independent peer review" and "independent validation," leaves a lack of clarity that can be exploited. Once again, EPA began to address the procedural and syntactical vagueness of the initial proposal by replacing the terms "replicate" and "reproducible" with "reanalyze" (Section 1C), as defined by the National Academy of Science Workshop Report (2016). Moreover, definitions for "independent peer review" and "independent validation" were adopted from the "Final Information 
Quality Bulletin for Peer Review" document released by OMB (Bolten 2004). These updates contributed clarity to the conceptual process by which EPA intends to evaluate studies. However, these improvements only began to address the issue, as there remains no description for how the review process would be executed. Further detailing the process will be an important step in placating critics.

\section{Recommendation: Alter the proposal}

We recommend that the proposal be further developed for reasons outlined in the section "Alter the Proposal." By addressing issues raised above and further developing the rule, it can truly tackle the issues it claims to be addressing.

First, EPA should take steps to build EPA-STRS in a way that removes science-dependent decisionmaking powers from political appointees, instead bestowing that power onto scientific experts. As recorded by a poll by the Pew Research Center, the general public trusts scientists at a higher rate than any other professional sector (see Figure 1, Funk et al. 2019). Therefore, the appointment of scientific experts to address scientific issues within the EPA would be a logical action, one that would bring the additional byproduct of building sustainable public trust with the rule, the regulatory process, and EPA as a whole. Specifically, we suggest that the rule could promote open data while addressing historical changes in best practices by granting an automatic exemption to all EPA funded data and models released FOUR (4) years prior to the date of final rule implementation - for research cited in current regulation - and FIVE (5) years prior to the conception of each new regulation. This is based on EPA's own guidelines for retention of data (5 years), minus one year for current rules to allow for a transition period for recent rules/studies.

Further, we suggest that these exemptions could be revoked, on a case by case basis, but only as deemed by a panel of appropriate scientific experts. This panel would be tasked with the assessment of "historical" data and/or models that may come into question, thus leaving the decision-making power to qualified experts. Finally, to stimulate public trust, any revocation of an exception, and the accompanying reasoning, should be made public to promote an open and transparent regulatory process.

\section{Americans' confidence that scientists act in the public interest is up since 2016}

\% of U.S. adults who say they have a great deal or fair amount of confidence in each of the following groups to act in the best interests of the public
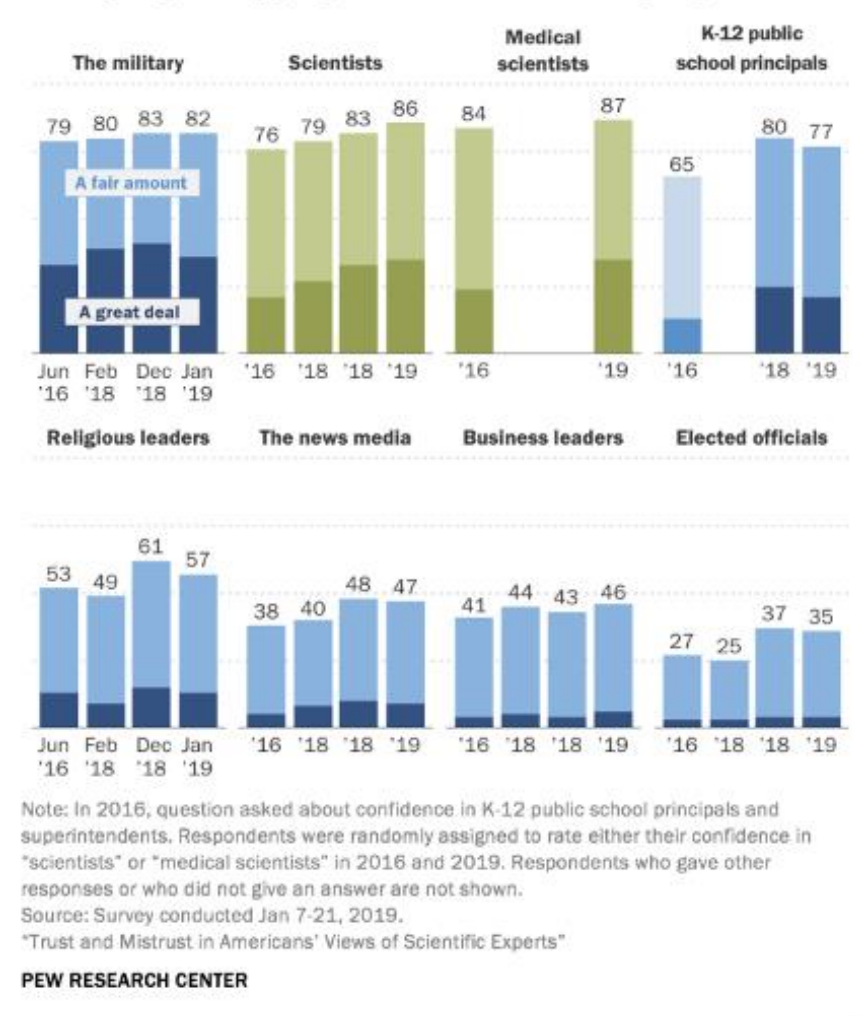

Figure 1: Polling data from Pew Research Center on public confidence in scientists (Funk et al. 2019.).

Another pertinent step is clarifying the problematic vagueness in the rule proposal. Namely, EPA must detail a mechanism by which "independent peerreview" would be conducted. We suggest that EPA partner with the National Institutes of Health (NIH) for this purpose. The NIH has a wealth of experience and expertise in the peer-review processes and could support developing both the conceptual underpinnings for enhanced peer-review processes and the procedure itself. Even though EPA has narrowed the scope of their intended "peer-review" to "reanalysis" in the SNPRM for EPA-STRS, a more meaningful and holistic approach could be developed with the NIH. In addition, the NIH's knowledge should be leveraged to construct a non-overlapping, robust, transparent, and conflict of interest free peer-review process.

Our recommendations take a constructive approach toward EPA-STRS, recognizing the merit in its goal to both confirm the conclusions of scientific studies for 
regulatory use and increase public trust through transparency. Since EPA uses science to make regulatory decisions that impact people's lives, it is

\section{References}

Administrative Procedures Act (APA), 5 USC $§ 551$ et seq 1946.

Allison, D. B., and Fineberg, H. V. 2020. "EPA's Proposed Transparency Rule: Factors to Consider, Many; Planets to Live on, One." Proceedings of the National Academy of Sciences 117 (10): 5084-87. https://doi.org/10.1073/pnas.1922721117

Anonymous. 1999. "Pros and Cons of Open Peer Review." Nature Neuroscience 2(3): 197-98. https://doi.org/10.1038/6295.

Anonymous. 2014. "Journals Unite for Reproducibility." Nature 515 (7525): 7-7. https://doi.org/10.1038/515007a.

Anonymous. 2016. "Repetitive Flaws." Nature 529 (7586): 256-256. https://doi.org/10.1038/529256a.

Baker, M. 2015. "Antibody Anarchy: A Call to Order." Nature 527 (7579): 545-51. https://doi.org/10.1038/527545a.

Bergeson and Campbell, PC. 2020. "EPA Releases Supplemental Proposed Rule to the Proposed Rule on Strengthening Transparency in Regulatory Science." The National Law Review. https://www.natlawreview.com/article/epareleases-supplemental-proposed-rule-toproposed-rule-strengthening-transparency.

Berry, D. 2016. "How Scientists Are Addressing the 'Reproducibility Problem.' Phys.org https://phys.org/news/2016-04-scientistsproblem.html.

Bloomer, L. 2020. "More Legal Questions in EPA's Supplemental Regulatory Science Proposal." Environmental \& Energy Law Program. https://eelp.law.harvard.edu/2020/04/morelegal-questions-in-epas-supplementalregulatory-science-proposal/.

Bolten, J. 2005. "Final Information Quality Bulletin for Peer Review" U.S. Executive Office of the President, Office of Management and Budget Memorandum for Heads of Departments and Agencies https://www.cio.noaa.gov/services programs/p dfs/OMB Peer Review Bulletin m05-03.pdf

Brugger, K.. 2020. "Trump Administration Expands Reach of EPA Secret Science Proposal." Scienc, Science \& Policy

https://www.sciencemag.org/news/2020/03/tr ump-administration-expands-reach-epa-secretscience-proposal important that this science be high-quality and the regulatory process be transparent.

Colbert, R. 1996. "Interpretation of the Good Laboratory Practice (GLP) Regulation GLP Regulations Advisory No. 76" Memorandum from the United states Environmental Protection Agency

Departmental Regulations, 5 U.S.C § 301 et seq 1958.

EPA. 2018. Strengthening Transparency in Regulatory Science; Proposed Rule. Federal Register (83 FR18768,) (FRL-9977-40) https://www.epa.gov/osa/strengtheningtransparency-regulatory-science

EPA. 2020. Supplemental Notice of Proposed Rulemaking (SNPRM) to Strengthening Transparency in Regulatory Science; Proposed Rule. Federal Registry (85 FR 15396) (FRL-10004-72-ORD) https://www.federalregister.gov/documents/20 20/03/18/2020-05012/strengtheningtransparency-in-regulatory-science $>$

Freedom of Information Act, 5 USC § 552. 1996.

Friedman, L. 2019. "E.P.A. to Limit Science Used to Write Public Health Rules." New York Times. https://www.nytimes.com/2019/11/11/climate Lepa-science-trump.html.

Funk, C., Hefferon, M., Kennedy, B., and Johnson, C. 2019. "Trust and Mistrust in Americans' Views of Scientific Experts". Pew Research Center. https://www.pewresearch.org/science/2019/08 $102 /$ trust-and-mistrust-in-americans-views-ofscientific-experts/.

Horgan, J. 2015. "Study Reveals Amazing Surge in Scientific Hype". Scientific American. https://blogs.scientificamerican.com/crosscheck/study-reveals-amazing-surge-in-scientifichype/.

Ioannidis, J. P. A. 2018. "All Science Should Inform Policy and Regulation". PLOS Medicine 15(5): e1002576. https://doi.org/10.1371/iournal.pmed.1002576.

Lilford, R. J., Richardson, A., Stevens, A., Fitzpatrick, R., Edwards, S., Rock, F., and Hutton, J. L. 2001. "Issues in Methodological Research: Perspectives from Researchers and Commissioners". Health Technology Assessment 5(8). https://doi.org/10.3310/hta5080.

Mcintyre, L. 2020. SCIENTIFIC ATTITUDE: Defending Science from Denial, Fraud, and Pseudoscience. S.L.: Mit Press. Massachusetts Institute of Technology. 
Miłkowski, M., Hensel, W. M., and Hohol, M. 2018.

"Replicability or Reproducibility? On the

Replication Crisis in Computational Neuroscience and Sharing Only Relevant Detail." Journal of Computational Neuroscience 45 (3): 163-72.

NAS (National Academies of Sciences, Engineering, and Medicine). 2016. Principles and obstacles for sharing data from environmental health research: Workshop summary. Washington, DC: The National Academies Press. https://doi.org/10.17226/21703.

NAS (National Academies of Sciences, Engineering, and Medicine). 2018. The Science of Science Communication III: Inspiring Novel Collaborations and Building Capacity: Proceedings of a Colloquium. Washington (DC): National Academies Press (US); .: https://www.ncbi.nlm.nih.gov/books/NBK50738 $1 /$.

National Institutes of Health (NIH). 2018, November 1. Update to NIH Management of Genomic Summary Results Access.

https://grants.nih.gov/grants/guide/noticefiles/NOT-OD-19-023.html.
Oreskes, N. 2019. Why Trust Science? Princeton, New Jersey: Princeton University Press.

Reilly, S., and News, E. E. 2019/ :EPA's Controversial 'Secret Science' Plan Still Lacks Key Details, Advisers Say." Science News. https://www.sciencemag.org/news/2019/08/ep a-s-controversial-secret-science-plan-still-lackskey-details-advisers-say.

United States. 1996. The Health Insurance Portability and Accountability Act (HIPAA). [Washington, D.C.]: U.S. Dept. of Labor, Employee Benefits Security Administration. 69 FR 78719 https://www.federalregister.gov/documents/20 04/12/30/04-28112/final-regulations-forhealth-coverage-portability-for-group-healthplans-and-group-health-insurance.

White, K. E., Robbins, C., Khan, B., and Freyman, C. 2017. "Science and Engineering Publication Output Trends: 2014 Shows Rise of Developing Country Output While Developed Countries Dominate Highly Cited Publications." National Science Foundation. https://www.nsf.gov/statistics/2018/nsf18300/

Samuel Herron is a graduate student at the University of Pittsburgh studying Cellular and Molecular Pathology. Sam holds a BS in Biology and Biochemistry from Virginia Polytechnic Institute and State University. He has served as the Treasurer of the Pitt Science Policy group for the last year, helping to organize events and manage funds for the group, and hopes to continue to serve the both group and the local Pittsburgh area for the remainder of his time in graduate school.

Jonathan F. Klonowski is a PhD graduate student researcher studying Congenital Heart Disease (CHD) at the University of Pittsburgh, School of Medicine. He employs a combination of computational and biological tools in order to investigate the role of ciliary signaling in CHD pathogenesis. Jonathan is the acting president of Pitt Science Policy group where he channels his passion for further integrating scientists at the local and national policy making process. Further to this, he is on the Diversity, Equity, and Inclusion Committee at the National Science Policy Network.

Cassandra Rios is a graduate student at the University of Pittsburgh pursing a PhD in Developmental Biology. She holds a B.S. in Genetics and Genomics from the University of California at Davis and was a Postbaccalaureate Fellow at the National Institutes of Health. Cassandra is a member of the Pitt Science Policy Group and plans to integrate her scientific background into a career in biotechnology-centered intellectual property law. 